\title{
Optimal Production and Inventory Policy in a Multiproduct Bakery Unit
}

\author{
Belmiro P. M. Duarte ${ }^{1,2, *(\mathbb{D}}$, André M. M. Gonçalves ${ }^{1}$ and Lino O. Santos ${ }^{2}$ (D) \\ 1 Department of Chemical and Biological Engineering, Coimbra Engineering Academy, Polytechnic Institute of \\ Coimbra, Rua Pedro Nunes, Quinta da Nora, 3030-199 Coimbra, Portugal; andremmgoncalves@gmail.com \\ 2 Centro de Investigação em Engenharia dos Processos Químicos e dos Produtos da Floresta, Department of \\ Chemical Engineering, University of Coimbra, Rua Sílvio Lima, Pólo II, 3030-790 Coimbra, Portugal; \\ lino@eq.uc.pt \\ * Correspondence: bduarte@isec.pt
}

check for updates

Citation: Duarte, B.P.M.;

Gonçalves, A.M.M.; Santos, L.O. Optimal Production and Inventory Policy in a Multiproduct Bakery Unit. Processes 2021, 9, 101. https://doi. org/10.3390/pr9010101

Received: 26 November 2020 Accepted: 28 December 2020 Published: 5 January 2021

Publisher's Note: MDPI stays neutral with regard to jurisdictional clai$\mathrm{ms}$ in published maps and institutional affiliations.

Copyright: $\odot 2021$ by the authors. Licensee MDPI, Basel, Switzerland. This article is an open access article distributed under the terms and conditions of the Creative Commons Attribution (CC BY) license (https:// creativecommons.org/licenses/by/ $4.0 /)$.

\begin{abstract}
The problem of finding optimal production and inventory policies is crucial for companies of the food industry, especially those processing multiple products. Since companies are required to adopt the most efficient solutions to prosper, the operation at these optimal conditions can have an extensive impact on profit, resource allocation and product quality. We address the problem of finding the optimal production and inventory policy in a multiproduct bakery unit for two contexts: (i) deterministic consumption without inventory control; and (ii) stochastic consumption combined with delayed inventory control. A formulation is proposed for each of these two setups. The restrictions considered in the model framework are related to workforce availability, and the cost structure includes four components: (i) production cost; (ii) inventory cost; (iii) setup cost; and (iv) the cost due to the degradation of perceived quality. The problem is formulated as a Mixed Integer Linear Programming one and solved with a branch and cut algorithm-based solver. The formulation is applied to a real bakery unit producing a mix of eight products. Distinct demand and inventory lower levels are used for building scenarios to test both models and characterize the economic performance of the multiproduct bakery unit.
\end{abstract}

Keywords: optimal production policy; inventory policy; multiproduct plant; food processing unit

\section{Motivation}

This paper addresses the problem of optimal design of the production and inventory policy of multiproduct processing units commonly found in the food industry sector. Namely, this problem finds application in small/medium size bakery units with the need of scheduling the production of various goods considering the available resources and guaranteing the quality is crucial. Typically, in order to assure the perceived quality level and optimize the cost structure of the production process, the connections between the production activity and inventory fluxes must be coordinated. Mathematical programming methods offer a reliable framework to handle the complexity and accomplish successfully the coordination of these production systems. Moreover, they provide a systematic framework that can be used to analyze the impact of plant and contextual external variables.

The design/redesign of food production/transformation units is influenced by several characteristics of the processes and products themselves [1]: (i) seasonality of the production; (ii) biological variation that require flexibility; (iii) quality preservation requirements; (iv) adequate conditions of transportation and storage; and (v) lot traceability to lower the impact of potential safety issues. The food network integrating production, storage and distribution/commercialization differs from that of other products, to the extent that the food quality is altered along the period between processing and consuming time. Effective quality, perceived quality (that results from sensorial customer experience in consuming 
the product) and safety are critical factors in food distribution/commercialization and the interdependence between them is critical [2].

The application of mathematical programming approaches in the context of designing food networks is scarce. Wouda et al. [3] proposed a model to optimize the production, transportation and units location for Nutricia Dairy \& Drinks Group. Ekşioğlu and Jin [4] address the problem of finding the optimal food distribution network accounting for production, setup, inventory and transportation costs, and van der Vorst et al. [1] integrate in an optimal design problem the logistics, sustainability metrics and quality analysis procedures. The optimal design of networks integrating production and distribution features, as well as quality degradation and temperature control, is discussed by Rong et al. [5]. Ahumada and Villalobos [6] addressed the problem of planning the production and tactical distribution decisions of fresh goods, and Amorim and Almada-Lobo [7] studied the lot-sizing and scheduling problem of food products where the perishability plays an important role in terms of operational decisions. Etemadnia et al. [8] analyzed the supply chain problem when bimodal transportation alternatives are considered. Most of these works focus on operational and tactical decisions given the characteristics of the goods. Another line of work in the literature exploits the inventory control and specifically the strategic decision of product release and storage, which are factors that play an important role regarding the product quality preservation [9]. Yan et al. [10] proposed an inventory model for controlling production and distribution decisions when processing a deteriorating good. A vast majority of studies reported in the literature consider the problem of distribution/production network design and production planning/scheduling. Only a few of these studies are related with perishable goods, which are seen as challenging problems in terms of model representation [11]. This complexity increases when uncertainty is incorporated in the model.

Among the studies addressing the optimal production/inventory/replenishment, Ali et al. [12] propose a logistic approach to handle the problem of inventory management of perishable goods where the basic aim is to determine an optimal replenishment schedule considering product deterioration and shortage. In the same line of research Coelho and Laporte [13] address the joint replenishment and delivery of perishable products, and propose a general Mixed Integer Linear Programming (MILP) model which is solved with a branch-and-cut algorithm. Hu et al. [14] formulate and analyze a model on a producer's dynamic inventory and markdown decisions for perishable goods. They consider a dynamic stochastic setting, where every scheduling period consists of two phases: (i) clearance; and (ii) regular-sales. The formulation of models for inventory level dependent demand rate was considered by Duan et al. [15], whom have established the necessary and sufficient conditions for the existence and uniqueness of the optimal solution. Shin et al. [16] have devised a dynamic inventory model which accounts for the uncertainty of supply and demand. The setup considers a two-phased inventory model for a food industry where the inventory is perishable, but can be renewed by additional processing. The design of supply chain networks for perishable goods under uncertainty was also addressed by Nguyen and Chen [17], Yavari and Geraeli [18], Chen et al. [19], among others. The problem of order sizing, crucial in inventory management, was addressed by Seubert et al. [20], among others. The authors use an Artificial Neural Network (ANN) to forecast the order size considering several input factors and use a bakery chain for demonstration. The problem of designing the optimal policies for production, inventory and replenishment of perishable goods was recently reviewed for example by Bakker et al. [21] and Janssen et al. [22].

Perceived quality is based on the perceptions of the product with respect to its quality attributes [23]. Typically, the consumer combines the sensorial experience of a product on the quality attributes with the weights associated to each attribute to form a quality judgment about the product [24]. Very often, the perceived quality degradation due to various factors such as products aging and conservation period have at least equal importance as the effective quality loss, commonly monitored by quantitative indicators. Both quality perspectives are interrelated but the former may affect the company image. 
Consequently, food production companies are paying increasing attention to perceived quality degradation as it is seen as a potential commercial loss [25].

Bakery units of small and medium size operate in multiproduct mode combined with fast distribution networks in order to preserve the perceived quality of the goods. Very often they face complex tactical decisions regarding the production sequencing (and scheduling) and inventory control in environments characterized by: (i) limited workforce availability; (ii) storage policies commonly requiring the preservation of products in freezing chambers at $-15^{\circ} \mathrm{C}$; (iii) perceived quality degradation in result of the preservation; and (iv) stochastic daily consumption which has direct impact on inventory level. Further, the bakery products fall into the perishable goods class, which are complex to model [11]. Very few published works report the design of optimal production and inventory policies for industrial food units with these characteristics. Studies addressing this kind of processing facilities appear to be lacking, and our paper intends to fill this void.

This paper contains four elements of novelty in regard to the optimal design problem formulation of the production and inventory policies of perishable goods. Firstly, the problem formulation relies on Resource Task Network (RTN) framework where a given time horizon of interest is discretized into slots and the events occur at their bounds. The inventory level is fixed (bounded from above) or operated in a reactive mode when the demand is stochastic. Moreover, the perceived quality loss due to product degradation in the freezing chamber is explicitly considered in cost model. Secondly, it takes into account the demand uncertainty. The demand is modeled with industrial data using an uniform probability distribution function (pdf) to construct stochastic demand scenarios over the time horizon. Thirdly, the proposed optimization formulation is demonstrated with a real problem that refers to a multiproduct Portuguese bakery production unit. Finally, this work contributes to devising guidelines for the specification of tactical production policies that may apply to other industrial multiproduct food units with similar characteristics.

The paper is organized as follows. Section 2 introduces the notation used to formulate the design problems as well as the models for both process operation setups. Section 3 presents the data set characterizing the demand and cost structure. Section 4 applies the formulations to find the optimal production and inventory policies. Several demand and minimum inventory level scenarios are simulated to gain a wider basis of knowledge subsequently used to improve the process operation specifications. Finally, Section 5 provides a summary of the results obtained with the proposed optimization model formulation and solving approach.

\section{Optimization Model}

This section first introduces the nomenclature used in the formulation of the mathematical models. Then, in Section 2.1 the model for determining the optimal production and inventory policy of multiproduct bakery units subject to deterministic demand, workforce limitations and minimum inventory level restrictions is presented. In Section 2.2 the model is extended to include stochastic consumption scenarios combined with delayed inventory control. Finally, the numerical approach used for solving the proposed model is reviewed.

Bold face lowercase letters represent vectors, capital letters matrices and blackboard bold capital letters discrete domains. Finite sets containing $\iota$ elements are compactly represented by $\llbracket \downarrow \rrbracket\{1, \cdots, \iota\} . \mathbb{N}$ is used to identify the set of positive integer numbers and $\mathbb{N}_{0}$ the set of non-negative integer numbers. The cardinality of a set is represented by $\operatorname{card}(\bullet)$ and the operation $z \equiv y(\bmod x)$ is used to represent the reminder of the division $y / x, y, x, z \in \mathbb{N}_{0}$. In Nomenclature, we list the indices, sets, parameters and variables used in the formulation of the optimization problems.

The production cost includes both the required raw materials and workforce costs, i.e., $c_{p, i}=c_{e, i}+c_{m, i}$. The setup cost refers to the cost of order assignment and production startup. The inventory cost is estimated from the power required by the freezing chamber taking into account the shelf space available and the average area occupied by products. Finally, the perceived quality degradation is estimated using guidelines approved in the 
company. Specifically, if a product unit is stored in the freezing chamber for a period of more than $\lambda \mathrm{d}$, the perceived quality degradation is such that the product cannot be commercialized, and its commercial value is lost. To determine the quality degradation cost on a daily basis we consider that the perceived quality behavior along the time is represented by a zero-order kinetic model as in Remmington [26]. Consequently, the degradation rate is constant on the time interval $[0, \lambda]$. Moreover, the perceived quality value is maximum immediately after the production, and is equal to the product selling price. That is, $c_{q, i}=p_{i} / \lambda, \forall i \in \mathbb{I}$. Further, we specify the availability of workforce such that $a_{t}=1$ for $t \in \mathbb{T}^{a}$ and 0 for $t \in \mathbb{T} \backslash \mathbb{T}^{a}$.

\subsection{Optimization Model for Deterministic Consumption without Inventory Control}

Here, we present the optimization model used for finding the optimal production policy when the product consumption is equal to the average demand, and there is no active control of the inventory level. The problem aims at determining: (i) the optimal production policy; and (ii) the optimal inventory policy that minimizes the overall cost for a pre-specified time horizon. The model formulation includes the specification of the following plant and contextual external variables: (i) the set of products to process; (ii) the production, setup, inventory and perceived quality degradation costs; (iii) the average daily consumption; (iv) the workforce availability; and (v) the batch time production of each product.

The planning production problem is modeled using a discrete-time representation [27]. Our formulation applies the fundamentals of the RTN representation, an unified framework for the description of a variety of process scheduling problems [28]. The time horizon, $H$, is discretized into $t^{\max }$ time slots (see Figure 1) of equal duration $\Delta t$ bounded by time events $t \in \mathbb{T}$. This set of time slots defines the time intervals where production activities may occur. Herein, the time slots correspond to days and the tasks correspond to production of a given product of the mix. The tasks can only be initiated and finished if the resources needed are available. The resources correspond to workforce and the freezing chamber. The $t$ th time slot starts at the event point $t-1$ and ends at the event point $t$ (Figure 1 ). The absolute time instants delimiting the tasks execution are specified by $\tau=\tau_{0}+t \Delta t, t \in \mathbb{T}$. Because the production process is cyclic, the solution that is prescribed at the event point $t^{\max }$ is equal to that of event point 0 .

\section{Continuous domain}

Time horizon $H$

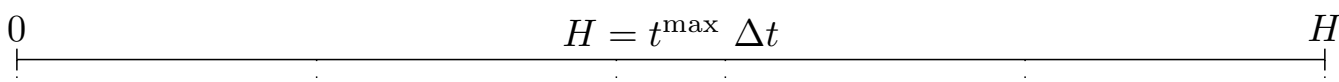

Time slots

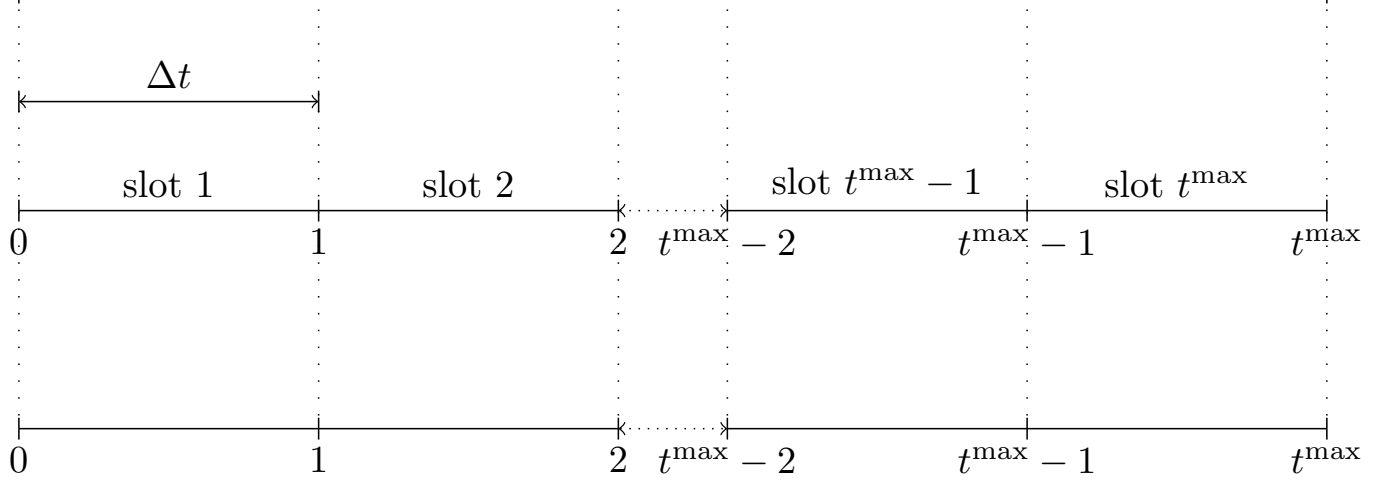

Discretized domain

Figure 1. Time discretization scheme.

We consider that the raw material availability is unlimited and the capacity of the freezing chamber is large enough so that it can be also considered unlimited. The resource 
workforce is necessary to carry out the production task, thus releasing product at the end of the operation. Then the released product either enters the distribution circuit or is stored in the freezing chamber. Later, when necessary to cover the demand, the product stored is used to feed the distribution circuit. The workforce resource availability is conditional (see Figure 2).

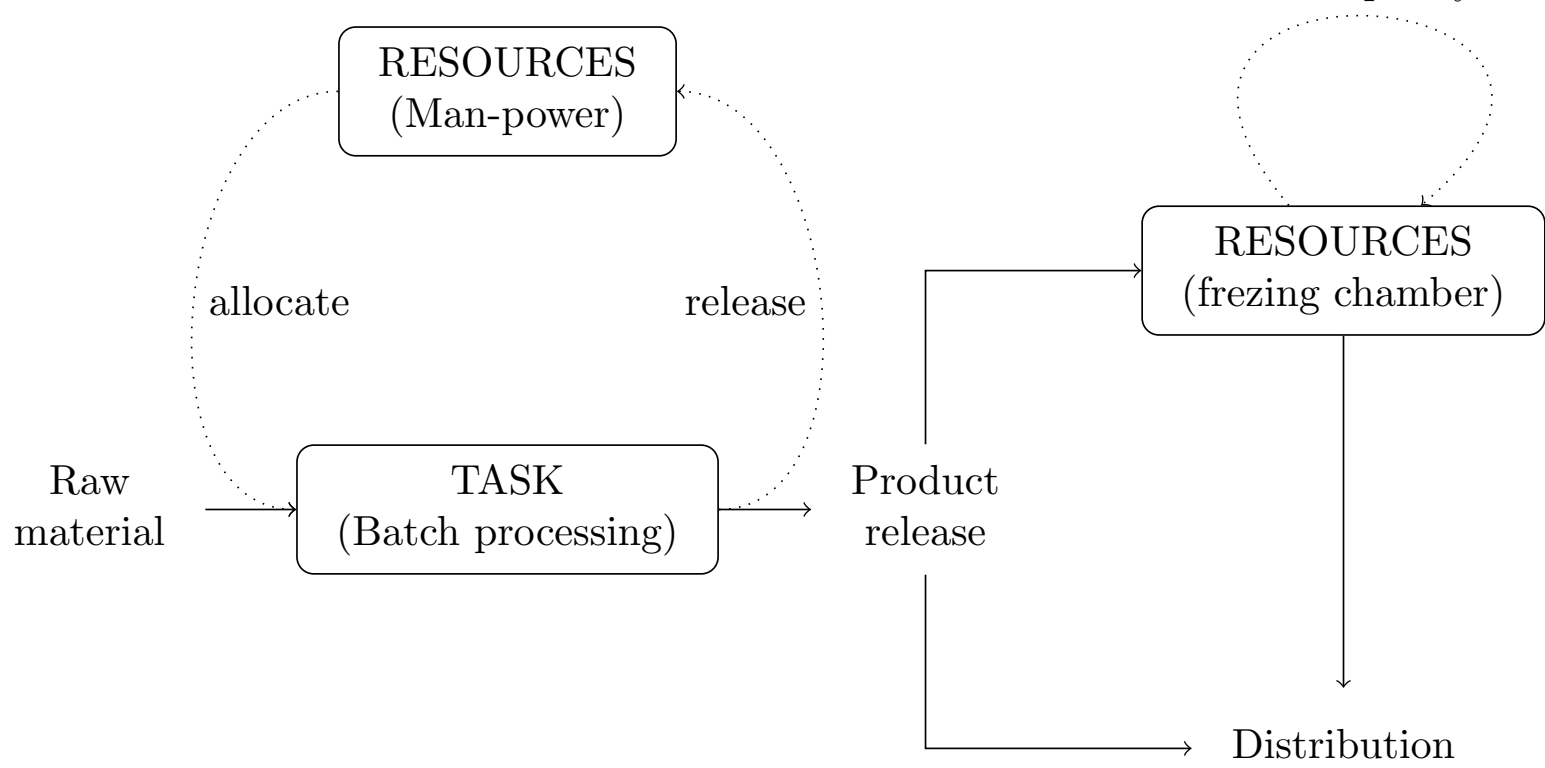

Figure 2. Resource-Task Network representation.

In this section we consider that the consumption is deterministic and is equal to the average daily demand. That is, for this setup it follows that $u_{t, i}=D_{i}^{\text {ref }}, \forall i \in \mathbb{I}, \forall t \in \mathbb{T}$. Further, the cost due to product deterioration on shelf is imputed to the perceived quality degradation. Herein, we consider a First In, First Out (FIFO) policy to manage the inventory in the freezing chamber which is in line with policies prescribed for food processing units [29]. Specifically, the product that is stored earlier is the first to enter the distribution in order to preserve the perceived quality and to reduce the amount of product with high storage time.

The model is formulated as a Mixed Integer Linear Program (MILP) where the objective is to minimize the sum of all costs subject to several constraints:

$$
\begin{aligned}
C=\min _{\mathbf{P}, \mathbf{R}, \mathbf{Y}} & \sum_{i} \sum_{t} P_{t, i} c_{p, i}+y_{t, i} c_{o, i}+R_{t, i}\left(c_{s, i}+c_{q, i}\right) \\
\text { s.t. } & P_{t, i}+R_{t-1, i}=R_{t, i}+D_{i}^{\mathrm{ref}}, \quad t \in \mathbb{T} \backslash\{1\}, i \in \mathbb{I} \\
& P_{1, i}+R_{\operatorname{card}(\mathbb{T}), i}=R_{1, i}+D_{i}^{\mathrm{ref}}, \quad i \in \mathbb{I} \\
& P_{t, i} \leq B y_{t, i}, \quad t \in \mathbb{T}, i \in \mathbb{I} \\
& y_{t, i} \leq b a_{t}, \quad t \in \mathbb{T}, i \in \mathbb{I} \\
& \sum_{i} y_{t, i} \theta_{i} \leq S, \quad t \in \mathbb{T} \\
& R_{t, i} \geq \gamma D_{i}^{\mathrm{ref}}, \quad t \in \mathbb{T}, i \in \mathbb{I}
\end{aligned}
$$

Equation (1a) is the objective function and combines the production, setup, inventory and perceived quality degradation costs. Equation (1b) is the balance holding for all time events but the first, while Equation (1c) is specifically for first event as it involves a circular operation on $\mathbb{T}$. Equation (1d) assigns batches to product release and Equation (1e) is to 
constrain batches realization to workforce availability. Equation (1f) constrains the number of batches produced per day to shift duration, and Equation (1g) imposes the minimum inventory level as a fraction $\gamma \in] 0,1]$ of the average daily demand.

\subsection{Optimization Model for Stochastic Consumption and Inventory Control}

Here, the optimization model in Section 2.1 is extended to deal with scenarios where the daily consumption is not equal to the average daily demand, and the inventory level is controlled to respond to product market oscillations. When the consumption is smaller than the production, the remaining amount of product is stored in the freezing chamber, increasing the inventory level. On the other hand, when the daily consumption is higher, the amount of product in deficit is compensated by product in stock which availability is assured by (positive) minimum inventory level. Afterwards, the inventory state is monitored and the amount of product to process in the next time slot $\Delta t$ is determined using the average daily demand (i.e., information from customers) and workforce availability (information from production department). Figure 3 shows the flows of material and information involved in this scenario. To safely accommodate the stochastic oscillations of the demand the producer needs to implement an inventory monitoring procedure and a decision support system to prescribe the order size on a daily basis. Naturally, this conceptualization is more realistic than the assumption of a deterministic demand where a minimum inventory level should be guaranteed to avoid stock ruptures. However, its implementation might require an operating procedure and slightly increases the complexity of the process.

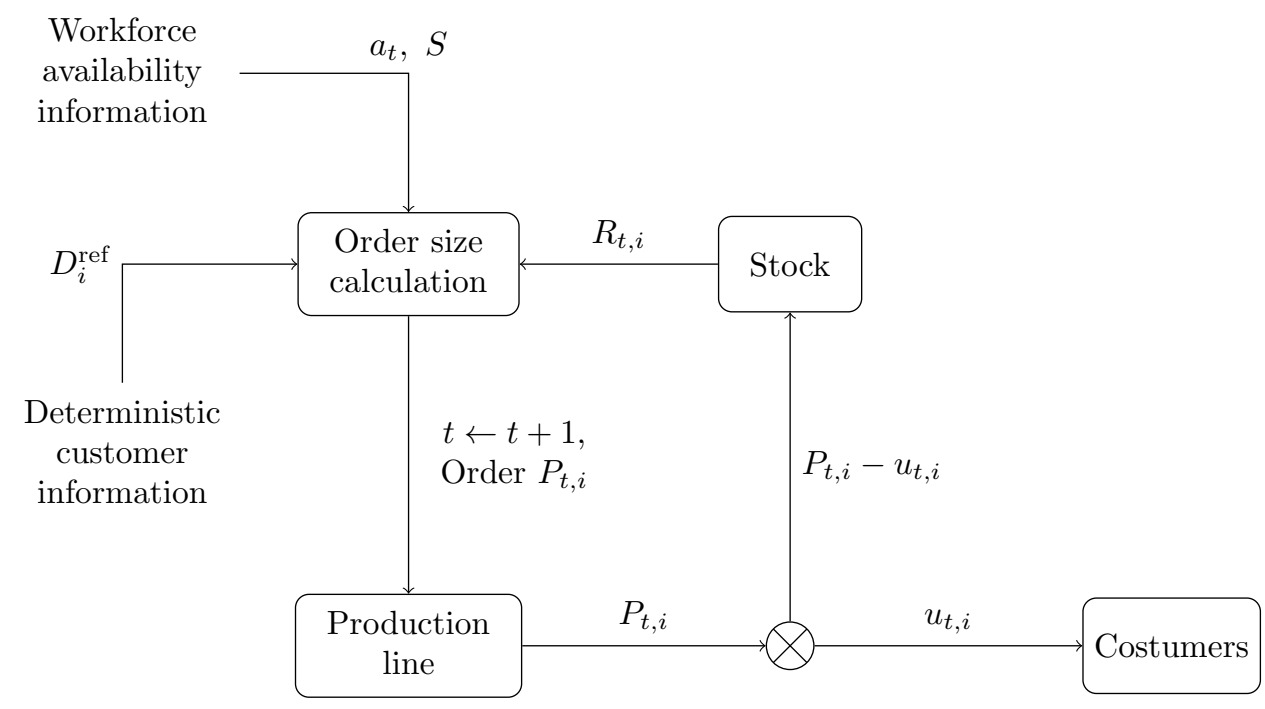

Figure 3. Inventory control scheme.

In practice the consumption is updated everyday. For simulation purposes the daily consumption is disaggregated into two components,

$$
u_{t, i}=D_{i}^{\mathrm{ref}}+z_{1-\alpha, t} \sigma_{i}
$$

where $D_{i}^{\text {ref }}$ is deterministic and the second term in Equation (2) is stochastic. Here, $z_{1-\alpha, t}$ is the inverse of the standard normal distribution computed for a specific confidence level $\alpha$ which, in turn, follows an uniform distribution in the interval [0.25, 0.75], i.e., $\alpha \sim \mathcal{U}[0.25,0.75]$. The rationale behind the stochastic component is that the consumption is uniformly distributed within the inter-quartile interval of the average daily demand. More stringent scenarios are not considered here as they may emulate specific (outlier) production occurrences. Practically, in our study the values of $\alpha$ are generated using an uniform random generator for the complete set of instances $\mathbb{T}$. Next, the values of $z_{1-\alpha, t}$ and $u_{t, i}$ are computed. The inventory control policy uses a prediction horizon of $\Delta t$ to 
adapt the production. That is, the consumption at time $t$ has an impact on the inventory level, and this information is used to decide on the production level at time instant $t+1$ (see Figure 3).

The model including inventory control is adapted from Equation (1) and accounts for the delayed feedback effect of consumption uncertainty, i.e.,

$$
\begin{aligned}
C=\min _{\mathbf{P}, \mathbf{R}, \mathbf{Y}} & \sum_{i} \sum_{t} P_{t, i} c_{p, i}+y_{t, i} c_{o, i}+R_{t, i}\left(c_{s, i}+c_{q, i}\right) \\
\text { s.t. } & P_{t, i}+R_{t-\delta, i}=R_{t, i}+u_{t, i}, \quad t \in \mathbb{T} \backslash \llbracket \delta \rrbracket, i \in \mathbb{I} \\
& P_{t, i}+R_{t+\operatorname{cord}(\mathbb{T})-\delta, i}=R_{t, i}+u_{t, i} \quad t \in \llbracket \delta \rrbracket, i \in \mathbb{I} \\
& \text { Equations (1d)-(1g), }
\end{aligned}
$$

where Equations (3b) and (3c) are mass balances and $u_{t, i}$ is given by Equation (2). Model Equation (3) generalizes the scheme to setups where the inventory information is integrated in decision making process when the delays are larger than 1, i.e., $\delta \geq 1$.

To determine the optimal operation policy for both setups, the MILP problems Equations (1) and (3) were coded in GAMS programming language environment [30]. The branch and cut algorithm-based solver CPLEX was used to solve the optimization problems. The CPLEX algorithm solves a series of Linear Programming (LP) subproblems [31,32] by employing the dual simplex method. The solver absolute and relative tolerances were set equal to $1 \times 10^{-8}$ and $1 \times 10^{-7}$, respectively. All the computations reported in Section 4 were performed in an Intel Core i7 machine running a 64 bits Windows 10 operating system with a $2.80 \mathrm{GHz}$ processor.

\section{Data}

In this section we list the data required by the model Equation (1). The data was gathered from a Portuguese bakery unit of middle size and refer to 8 non-seasonal sweet baked food products. The bakery production process involves three main stages: (i) mixing the ingredients after convenient mise en place; (ii) baking (when necessary); and (iii) final assemblage which might require glazing, coating and decorating some elements. When the quality level of the products is considered below the standard during the production process they are immediately declassified and treated as internal non-conformities. Consequently, they are not expedited to clients or even enter the inventory. Thus, the faulty production is considered marginal in this study and practically neglected in the model. The quality loss accounted for in the cost model is due to the (excessive) time the products are in the freezing chamber before consumption.

All the cost components, workforce availability, selling price and other operation parameters were determined from data on the antecedent bakery operation. The average daily demand was determined from data gathered during 3 months. For discrimination,

\begin{tabular}{|c|c|c|c|c|c|c|c|c|}
\hline & \multicolumn{8}{|c|}{ Products } \\
\hline & A & B & $\mathrm{C}$ & D & E & $\mathbf{F}$ & G & $\mathrm{H}$ \\
\hline$c_{m}$ (€/unit) & 0.2625 & 0.3184 & 0.0958 & 0.1729 & 0.1601 & 0.1229 & 0.551 & 0.551 \\
\hline$c_{e}(€ /$ unit $)$ & 0.0179 & 0.0309 & 0.0061 & 0.0802 & 0.1507 & 0.0310 & 0.0025 & 0.0441 \\
\hline$c_{b}(€ /$ batch $)$ & 1.0714 & 0.6786 & 1.4286 & 0.7857 & 0.7900 & 1.4286 & 2.7857 & 2.78 \\
\hline$c_{s}(€ /$ unit.d $)$ & 0.000162 & 0.000162 & 0.000162 & 0.000162 & 0.000162 & 0.000162 & 0.000162 & 0.000162 \\
\hline$p(€ /$ unit $)$ & 0.37 & 0.55 & 0.37 & 0.46 & 0.46 & 0.46 & 0.37 & 0.41 \\
\hline$D^{\text {ref }}$ (units /d) & 144 & 13 & 55 & 4 & 8 & 7 & 41 & 5 \\
\hline$\sigma$ (units/d) & 57 & 3 & 35 & 2 & 2 & 2 & 14 & 1 \\
\hline$\theta(\mathrm{h})$ & 4.0 & 3.0 & 3.0 & 3.5 & 3.5 & 2.5 & 2.5 & 2.5 \\
\hline
\end{tabular}
the products are assigned to letters (A to $\mathrm{H})$. The complete data set is given in Table 1. The row for $\sigma$ contains the standard deviation of the average daily demand.

Table 1. Data for the bakery unit optimization model (A, B, ..., $\mathrm{H}$ are products).

We set $H=28 \mathrm{~d}$ (4 weeks) as it seems to be a time horizon large enough to capture cyclic behaviors. Further, $\Delta t=1 \mathrm{~d}, \tau_{0}$ is $0 \mathrm{~d}$ and corresponds to Sunday. The workforce 
availability is allocated to instances $t$ corresponding to working days counted cyclically from Monday. The allocation of workforce using the discretized representation of Figure 1 allows setting $\mathbb{T}^{a} \equiv\{t: t \in \mathbb{T}, t(\bmod 7) \in \llbracket 5 \rrbracket\}$, and assigning $a_{t}, t \in \mathbb{T}$. $B$ is set to 400 units, corresponding to the maximum number of items produced per batch. On the other hand, the maximum number of batches of a single product processed in a day, $b$, is set to 8 , and is only constrained by workforce availability. The shift, $S$, is set by the bakery with a duration of $7.5 \mathrm{~h}$. The minimum inventory level is $10 \%$ of the average daily demand for all products, i.e., $\gamma=0.10$. The perceived quality is zero after a period of storage of $\lambda=14 \mathrm{~d}$ in the freezing chamber. Consequently, the remaining commercial value of the product is null for $\lambda>14 \mathrm{~d}$.

\section{Results}

This section presents the optimal production and inventory policies obtained with models Equations (1) and (3). First, we address the setup where the consumption is deterministic and equal to average daily demand (see the sixth row of Table 1) and use model Equation (1) for three scenarios of consumption. Next, the model Equation (3) is adopted for a setup where the consumption is stochastic and a delayed inventory control policy is implemented.

To analyze the first setup we consider three consumption scenarios: (i) consumption equal to average daily demand (sixth row of Table 1), designated by $\mathrm{SC}_{\mathrm{D}}$; (ii) consumption equal to the $25 \%$ quartile of the average daily demand, $\mathrm{SC}_{\mathrm{D}^{-}}$; and (iii) consumption equal to the $75 \%$ quartile, $\mathrm{SC}_{\mathrm{D}^{+}}$. Additionally, a fourth scenario is simulated, $\mathrm{SC}_{\mathrm{I}^{+}}$, where the reference conditions of $S_{D}$ are imposed while the minimum inventory level is increased to $15 \%$. The reference scenario $S_{\mathrm{D}}$ is first analyzed in deep as it reveals features that can be well advantageous to implement in the bakery production line. This reference scenario will be used for comparison against the other three scenarios.

Figure 4 shows the production and inventory profiles over the time horizon that were obtained for the production scenario of reference, $\mathrm{SC}_{\mathrm{D}}$. Two distinct plots are presented side by side because products $\mathrm{A}, \mathrm{C}$ and $\mathrm{G}$ have higher daily production rates (and inventory levels). One observes that the profiles for products with higher production rates follow a weekly cyclic policy, well captured by the simulation of a 4 weeks-based horizon. Contrarily, the other products do not follow a weekly cyclic pattern and its schedule should be planned in a larger time horizon as is a 4 week period.

The production of $\mathrm{A}$, which has the larger demand, is prescribed to occur two days of the week to reduce the inventory and perceived quality degradation cost, while for the other products the schedule is adapted to human resources availability. Practically, the optimal policy prescribes producing a single batch per week of products with smaller demand and two batches per week of products with intermediate demand. The production of all products except A is higher at the end of week (Thursday and Friday) so that the inventory allows satisfying the demand during the weekend when the production is canceled due to the workforce availability restrictions and the perceived quality degradation cost is minimized.

Figure 5 presents the assignment of batches to week days. The products with higher demand are processed with intervals of two or threes days given the constraints on workforce and shift duration and the others only once per week. The maximum number of products processed per day is 3 and a single batch of each one is enough to satisfy the demand and keep the perceived quality cost at minimum. As example of efficiency of the numerical strategy used, the MILP problem solved for this scenario involves 673 constraints, 701 variables and the solution convergence takes 10.66 s of CPU.

Now, we consider the other three scenarios, with higher and lower daily bakery product consumption, respectively $\mathrm{SC}_{\mathrm{D}^{+}}$and $\mathrm{SC}_{\mathrm{D}^{-}}$, and with minimum inventory level, $\mathrm{SC}_{\mathrm{I}^{+}}$. As for the new values of consumption, these are estimated from $D_{i}^{\text {ref }}, \forall i \in \mathbb{I}$, and the respective standard deviation, $\sigma_{i}$ (see Table 1 ). For the scenario $\mathrm{SC}_{\mathrm{D}^{-}}$, the lower bound 
consumption is specified such that $u_{t, i}=D_{i}^{\text {ref }}-z_{1-\alpha} \sigma_{i}, \forall i \in \mathbb{I}$, and $z_{1-\alpha}=0.6745$. For the scenario $\mathrm{SC}_{\mathrm{D}^{+}}$, the upper bound consumption is set such that $u_{t, i}=D_{i}^{\text {ref }}+z_{1-\alpha} \sigma_{i}, \forall i \in \mathbb{I}$.

Table 2 shows the optimal overall cost for a $28 \mathrm{~d}$ production horizon of each production scenario. It is noteworthy to mention: (i) the decrease of the overall cost when the demand is reduced, as expected; and (ii) a slight cost increase (about $0.4 \%$ ) when the minimum inventory level is increased by $5 \%$ with respect to the average daily demand. Table 3 shows the relative importance of the cost components in the overall cost structure. The production costs including raw materials and labor dominate, whereas the setup cost represents about $2 \%$ of the total cost, and the perceived quality degradation cost represents almost $12 \%$. The inventory cost is practically negligible because (i) the mean time of the products in the freezing chamber is relatively small; (ii) given its storage capacity, the cost of operating the freezing chamber per unit of product is quite low.

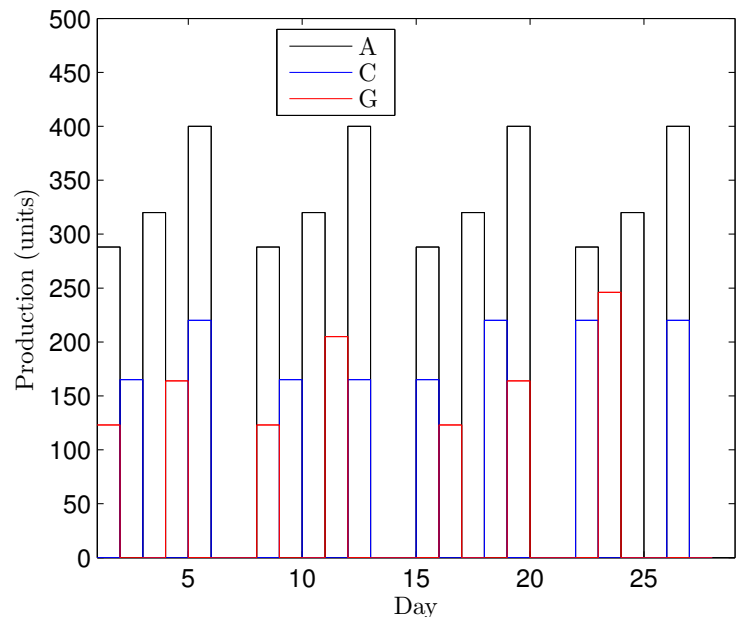

(a)

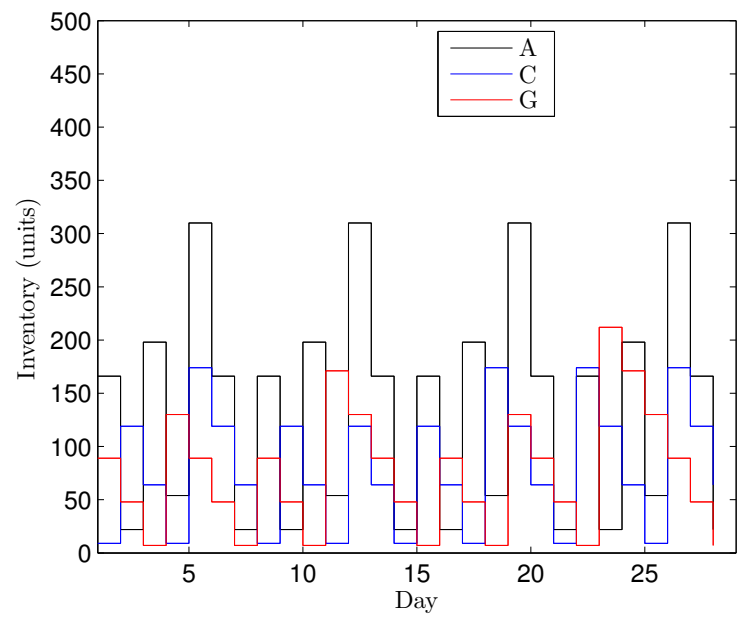

(c)

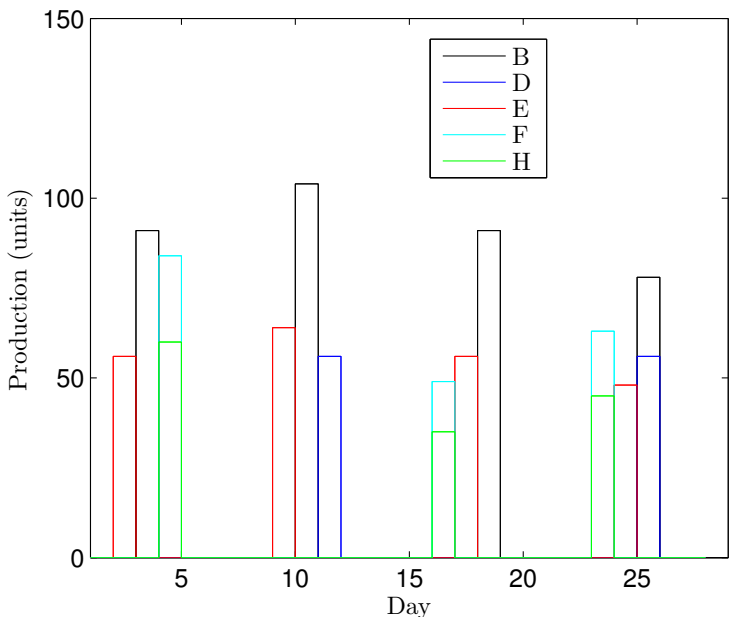

(b)

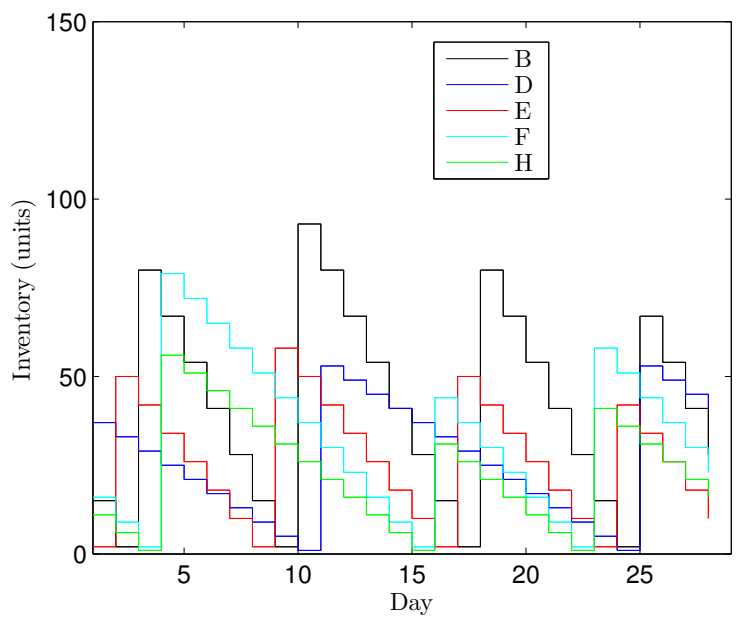

(d)

Figure 4. Optimal profiles for production and inventory levels with a deterministic consumption and without inventory control: (a) Production of A, C, G; (b) Production of B, D, E, F, H; (c) Inventory of A, C, G; (d) Inventory of B, D, E, F, H. 


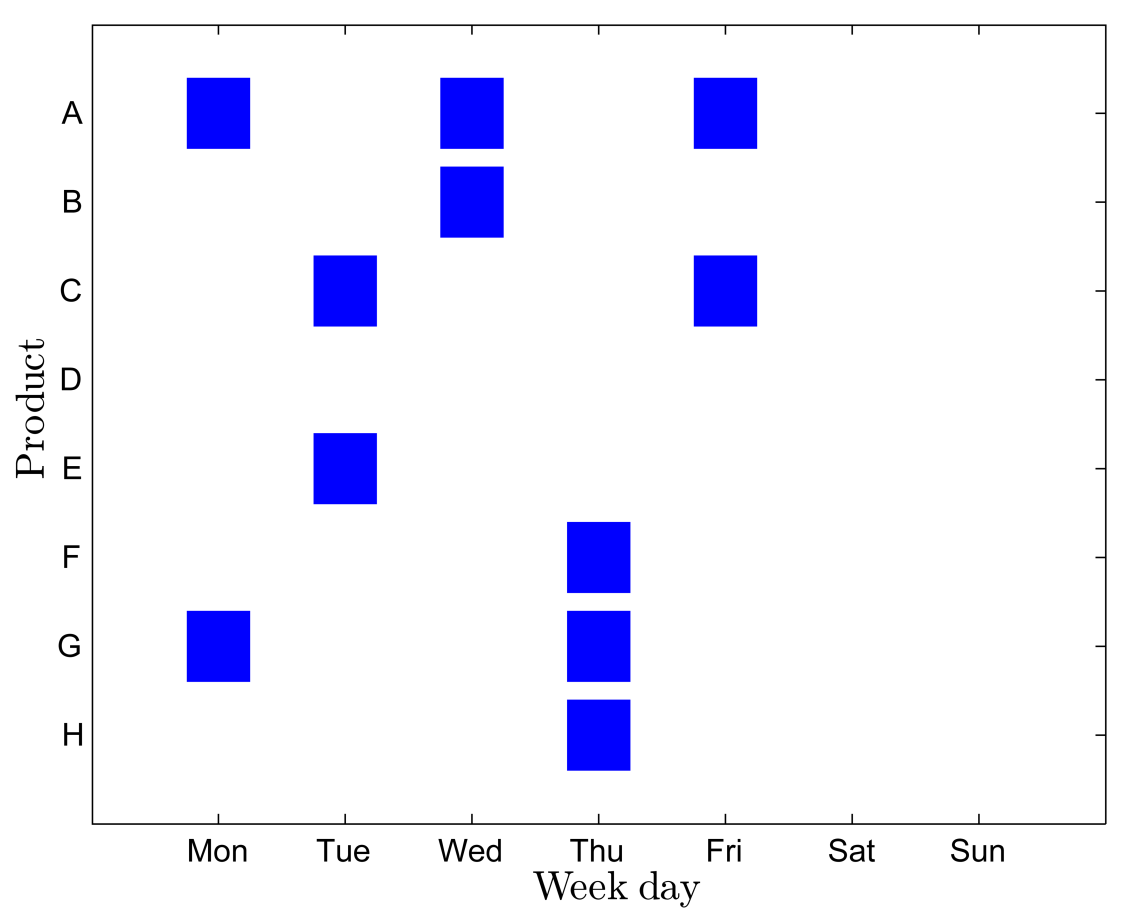

Figure 5. Assignment of batches to week days for deterministic (and stochastic) consumption without inventory control.

Table 2. Overall optimal cost for $28 \mathrm{~d}$ production horizon.

\begin{tabular}{clc}
\hline Scenario & Conditions & Cost $(€)$ \\
\hline$S C_{D}$ & Average daily demand $\left(D_{i}=D_{i}^{\text {ref }}, \forall i \in \mathbb{I}\right) ; \gamma=0.1$ & $2.673 \times 10^{3}$ \\
$S C_{D+}$ & $75 \%$ quartile $\left(D_{i}=D_{i}^{\text {ref }}+0.6745 \sigma_{i}, \forall i \in \mathbb{I}\right) ; \gamma=0.1$ & $3.439 \times 10^{3}$ \\
$S C_{D-}$ & $25 \%$ quartile $\left(D_{i}=D_{i}^{\text {ref }}-0.6745 \sigma_{i}, \forall i \in \mathbb{I}\right) ; \gamma=0.1$ & $2.043 \times 10^{3}$ \\
$S C_{I+}$ & Average daily demand $\left(D_{i}=D_{i}^{\text {ref }}, \forall i \in \mathbb{I}\right) ; \gamma=0.15$ & $2.684 \times 10^{3}$ \\
\hline
\end{tabular}

Table 3. Importance of cost components relative to overall optimal cost for $28 \mathrm{~d}$ production horizon (deterministic consumption combined with absence of inventory control).

\begin{tabular}{cccccc}
\hline \multirow{2}{*}{ Scenario } & \multicolumn{5}{c}{ Cost Component (\%) } \\
\cline { 2 - 6 } & Production & Setup & Inventory & Quality & Total \\
\hline$S C_{D}$ & 84.59 & 2.39 & 0.07 & 12.94 & 100 \\
$S C_{D+}$ & 83.63 & 1.79 & 0.08 & 14.45 & 100 \\
$S C_{D-}$ & 84.11 & 3.16 & 0.07 & 12.66 & 100 \\
$S C_{I+}$ & 84.26 & 2.37 & 0.07 & 13.29 & 100 \\
\hline
\end{tabular}

Finally, we test model Equation (3) for a scenario with stochastic consumption and delayed inventory control. The daily consumption is generated using the approach described in Section 2.2. The profiles of production and inventory levels are equal to those of presented in Figure 6. In result of the consumption uncertainty, the plots show that there is not an obvious operation cycle. However, the main features of the production policy are similar to those found for the deterministic consumption case. Finally, we note that the corresponding batch assignment sequence obtained for the stochastic consumption scenario is equal to the one prescribed for the deterministic consumption; see Figure 5.

Table 4 presents the results obtained for different minimum inventory levels and two values of control delay, $\delta=1$ and $\delta=2$. Recall that $\gamma$ is set to 0.10 in the scenario $\mathrm{SC}_{\mathrm{D}}$, whereas in $\mathrm{SC}_{\mathrm{I}^{+}}$it is $\gamma=0.15$. The optimal overall costs obtained for the stochastic consumption scenario are slightly higher than those for the deterministic demand scenario 
(compare the first line of Tables 3 and 4), but the observed trends are similar. Specifically, the cost structure is similar, and the production cost over the time horizon denotes a slight increase (about $0.4 \%$ ) when the minimum inventory is changed from $10 \%$ to $15 \%$ of the average daily demand. A minimum inventory level of $10 \%$ is sufficient to accommodate the consumption variability when the control delay is of $1 \mathrm{~d}$. In the case of higher control delays as when $\delta=2$ (see the last two rows of Table 4) the inventory profile becomes smoother. That is, this production scenario is less susceptible to excessive and reactive production decisions. Consequently, the quality degradation cost slightly decreases.

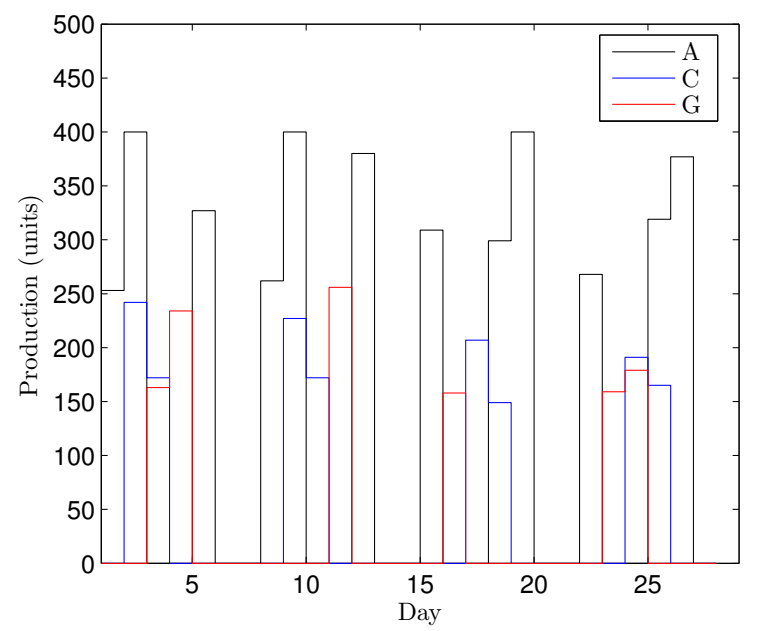

(a)

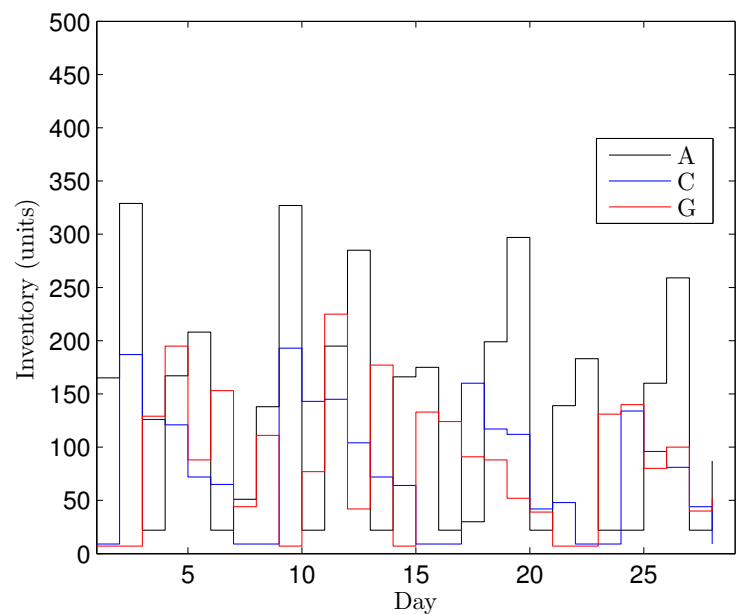

(c)

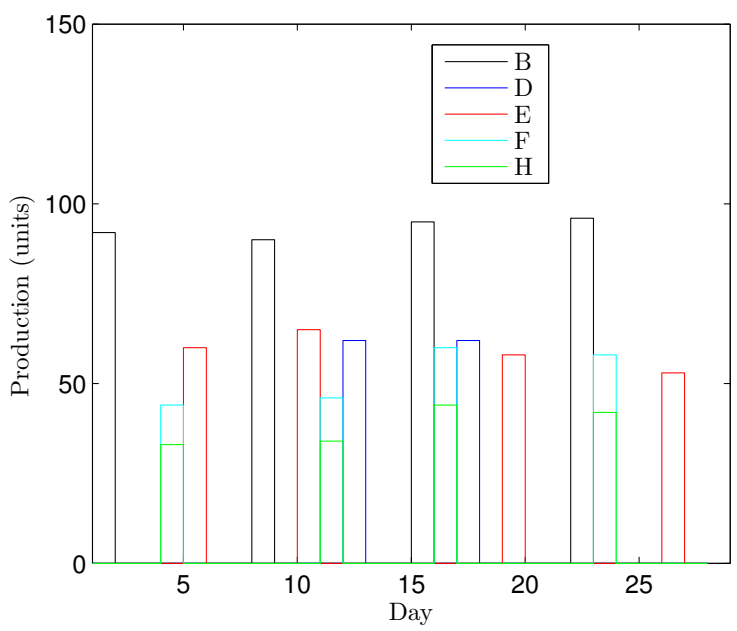

(b)

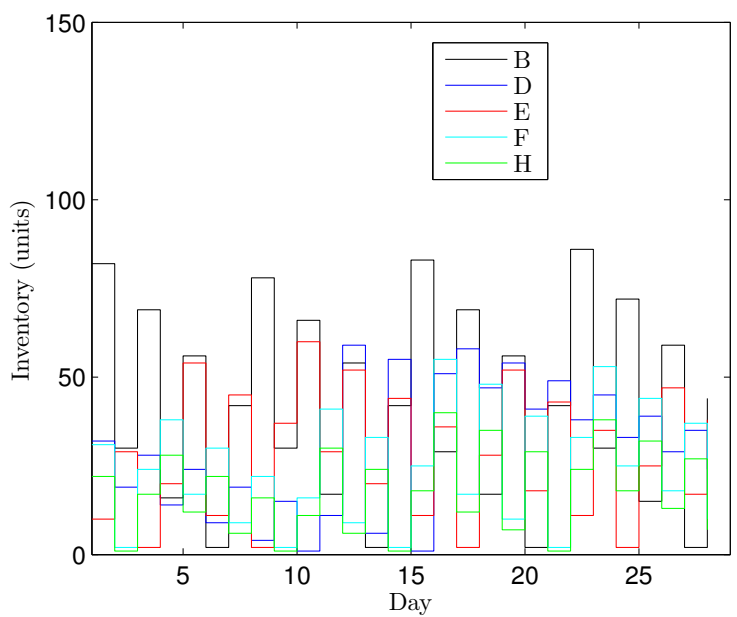

(d)

Figure 6. Optimal profiles for production and inventory levels for stochastic consumption with delayed inventory control: (a) Production of A, C, G; (b) Production of B, D, E, F, H; (c) Inventory of A, C, G; (d) Inventory of B, D, E, F, H.

Table 4. Importance of cost components relative to overall optimal cost for $28 \mathrm{~d}$ production horizon (stochastic consumption and delayed inventory control).

\begin{tabular}{|c|c|c|c|c|c|c|}
\hline \multirow{2}{*}{ Scenario } & \multirow{2}{*}{ Delay $(\delta)$} & \multicolumn{4}{|c|}{ Cost Component (\%) } & \multirow{2}{*}{ Cost $(€)$} \\
\hline & & Production & Setup & Inventory & Quality & \\
\hline$S C_{D}$ & 1 & 84.27 & 2.42 & 0.07 & 13.24 & $2.693 \times 10^{3}$ \\
\hline$S C_{I+}$ & 1 & 83.94 & 2.41 & 0.08 & 13.57 & $2.704 \times 10^{3}$ \\
\hline$S C_{D}$ & 2 & 84.59 & 2.43 & 0.07 & 12.91 & $2.682 \times 10^{3}$ \\
\hline$S C_{I+}$ & 2 & 84.25 & 2.42 & 0.07 & 13.25 & $2.693 \times 10^{3}$ \\
\hline
\end{tabular}




\section{Conclusions}

We consider the problem of determining the optimal production and inventory policy of multiproduct food processing units. Two setups are considered (i) deterministic demand and without inventory control; and (ii) stochastic daily consumption combined with delayed inventory control. The proposed model formulations include (i) the workforce limitations; and (ii) a cost structure with four terms: production cost, setup cost, storage cost and perceived quality degradation cost. The last term is used to characterize the sensorial loss of product quality when consumed and is commonly associated to long periods of preservation in freezing chambers.

The model optimization formulations are tested with real data from a bakery unit processing 8 sweet baked food products. The numerical solutions for a time horizon of four weeks reveal that (i) the cost structure is dominated by production cost (weights more than $80 \%$ of the overall cost), and the inventory cost of storing product in the freezing chamber is negligible; (ii) the optimal batch sequence requires producing the most consumed pastries three times per week, and the less consumed ones once per week; (iii) the optimal sequence for the deterministic demand setup shows a cyclic profile that can be used for constructing an operation procedure, and subsequently implemented on site on a per week basis; and (iv) the results obtained for the stochastic consumption with delayed inventory control are similar to those found for the deterministic demand scenario. The main difference is that in the stochastic consumption scenario it is not possible to operate based in weekly campaigns. Contrarily, it requires reactive decisions on a daily basis and an effective inventory monitoring. To summarize, the deterministic demand scenario might be unrealistic but simplifies the work organization, while the stochastic demand combined with delayed inventory control is more realistic but difficult to standardize as a procedure.

Author Contributions: B.P.M.D.-Conceptualization, Formal analysis, Methodology, Writing; A.M.M.G.-Data curation, Investigation, Review and editing; L.O.S.--Validation, Review and editing. All authors have read and agreed to the published version of the manuscript.

Funding: This research received no external funding.

Informed Consent Statement: Informed consent was obtained from all subjects involved in the study.

Conflicts of Interest: The authors declare no conflict of interest.

$\begin{array}{ll}\text { Nomenclature } & \\ \text { Indices } & \text { time instant } \\ t & \text { product } \\ i & \\ \text { Sets } & \text { set of discrete time instants } \\ \mathbb{T} \equiv\left\{t: t \in \llbracket t^{\max \rrbracket\}}\right. & \text { set of discrete time instants where workforce is available } \\ \mathbb{T}^{a} \in \mathbb{T} & \text { set of products } \\ \mathbb{I} \equiv\left\{i: i \in \llbracket i^{\max } \rrbracket\right\} & \\ \text { Parameters } & \text { number of products } \\ i^{\max } & \text { number of discrete time instants in } H \\ t^{\text {max }} & \text { discretization interval }(\mathrm{d}) \\ \Delta t & \text { number of discrete time instants of the inventory control delay } \\ \delta & \text { absolute time instant }(\mathrm{d}) \\ \tau_{t}=\tau_{0}+t \Delta t & \text { time horizon }(\mathrm{d}) \\ H & \text { energy cost }(€ / \text { unit) } \\ c_{e, i} & \text { raw material cost }(€ / \text { unit) } \\ c_{m, i} & \text { production cost }(€ / \text { unit }) \\ c_{p, i} & \text { batch setup cost }(€ / \text { batch) } \\ c_{0, i} & \end{array}$




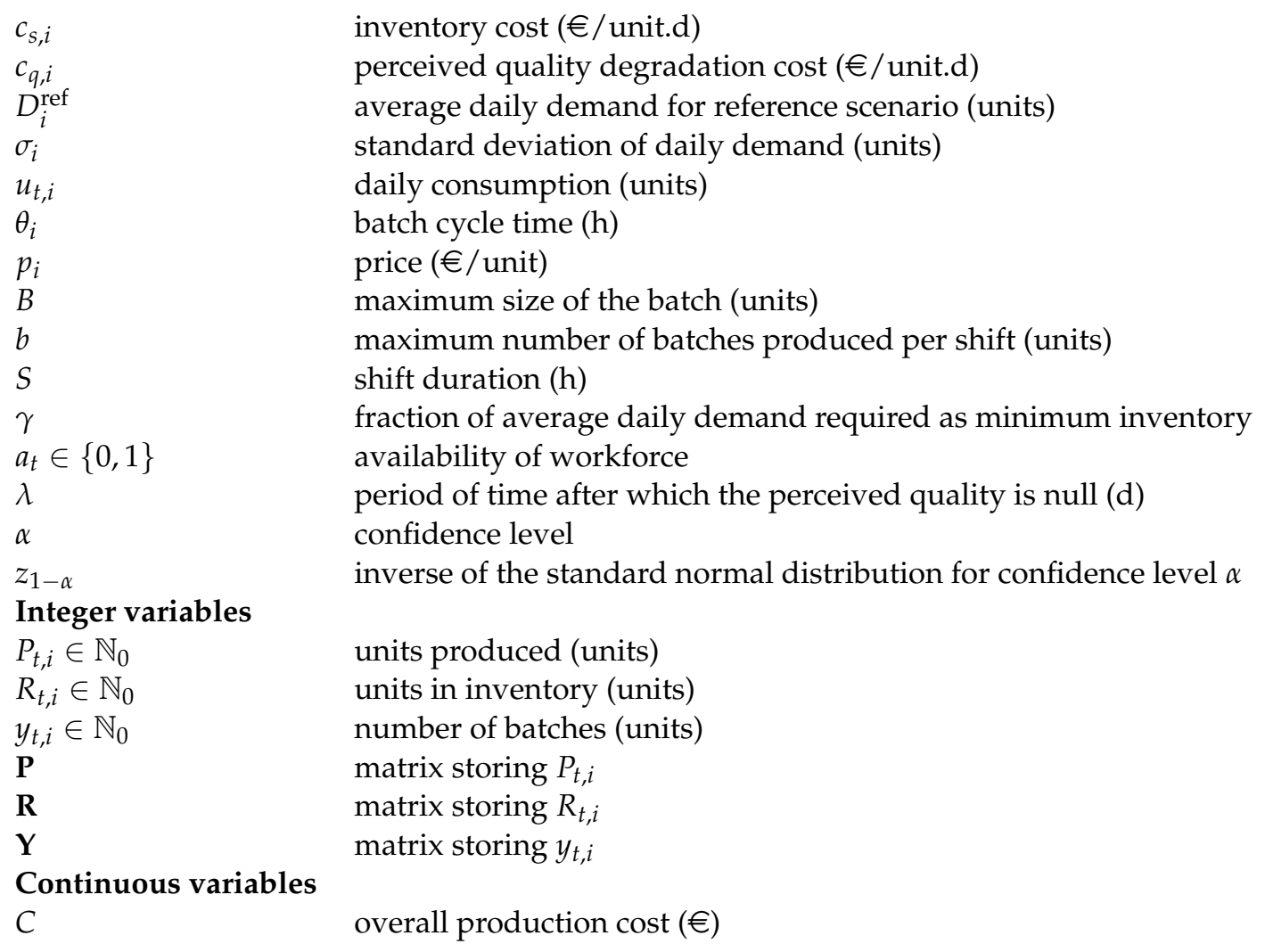

\section{References}

1. Van der Vorst, J.G.; Tromp, S.O.; van der Zee, D.J. Simulation modelling for food supply chain redesign; integrated decision making on product quality, sustainability and logistics. Int. J. Prod. Res. 2009, 47, 6611-6631. [CrossRef]

2. Akkerman, R.; Farahani, P.; Grunow, M. Quality, safety and sustainability in food distribution: A review of quantitative operations management approaches and challenges. OR Spectr. 2010, 32, 863-904. [CrossRef]

3. Wouda, F.; van Beek, P.; van der Vorst, J.; Tacke, H. An application of mixed-integer linear programming models on the redesign of the supply network of Nutricia Dairy \& Drinks Group in Hungary. OR Spectr. 2002, 24, 449-465.

4. Ekşioğlu, S.D.; Jin, M. Cross-facility production and transportation planning problem with perishable inventory. In Proceedings of the Computational Science and Its Applications-ICCSA 2006, Glasgow, UK, 8-11 May 2006; Gavrilova, M., Gervasi, O., Kumar, V., Tan, C.J.K., Taniar, D., Laganá, A., Mun, Y., Choo, H., Eds.; Springer: Berlin/Heidelberg, Germany, 2006 ; pp. 708-717.

5. Rong, A.; Akkerman, R.; Grunow, M. An optimization approach for managing fresh food quality throughout the supply chain. Int. J. Prod. Econ. 2011, 131, 421-429.

6. Ahumada, O.; Villalobos, J.R. A tactical model for planning the production and distribution of fresh produce. Ann. Oper. Res. 2011, 190, 339-358. [CrossRef]

7. Amorim, P.; Almada-Lobo, B. The impact of food perishability issues in the vehicle routing problem. Comput. Ind. Eng. 2014, 67, 223-233.

8. Etemadnia, H.; Goetz, S.; Canning, P.; Tavallali, M.S. Optimal wholesale facilities location within the fruit and vegetables supply chain with bimodal transportation options: An LP-MIP heuristic approach. Eur. J. Oper. Res. 2015, 244, 648-661. [CrossRef]

9. Blackburn, J.; Scudder, G. Supply chain strategies for perishable products: The case of fresh produce. Prod. Oper. Manag. 2009, 18, 129-137. [CrossRef]

10. Yan, C.; Banerjee, A.; Yang, L. An integrated production-distribution model for a deteriorating inventory item. Int. J. Prod. Econ. 2011, 133, 228-232. [CrossRef]

11. Amorim, P.; Meyr, H.; Almeder, C.; Almada-Lobo, B. Managing perishability in production-distribution planning: A discussion and review. Flex. Serv. Manuf. J. 2013, 25, 389-413. [CrossRef]

12. Ali, S.S.; Madaan, J.; Chan, F.T.; Kannan, S. Inventory management of perishable products: A time decay linked logistic approach. Int. J. Prod. Res. 2013, 51, 3864-3879. [CrossRef]

13. Coelho, L.C.; Laporte, G. Optimal joint replenishment, delivery and inventory management policies for perishable products. Comput. Oper. Res. 2014, 47, 42-52. [CrossRef]

14. Hu, P.; Shum, S.; Yu, M. Joint Inventory and Markdown Management for Perishable Goods with Strategic Consumer Behavior. Oper. Res. 2016, 64, 118-134.

15. Duan, Y.; Li, G.; Tien, J.M.; Huo, J. Inventory models for perishable items with inventory level dependent demand rate. Appl. Math. Model. 2012, 36, 5015-5028. 
16. Shin, M.; Lee, H.; Ryu, K.; Cho, Y.; Son, Y.J. A two-phased perishable inventory model for production planning in a food industry. Comput. Ind. Eng. 2019, 133, 175-185. [CrossRef]

17. Nguyen, D.H.; Chen, H. An effective approach for optimization of a perishable inventory system with uncertainty in both demand and supply. Int. Trans. Oper. Res. 2020. [CrossRef]

18. Yavari, M.; Geraeli, M. Heuristic method for robust optimization model for green closed-loop supply chain network design of perishable goods. J. Clean. Prod. 2019, 226, 282-305.

19. Chen, K.; Xiao, T.; Wang, S.; Lei, D. Inventory strategies for perishable products with two-period shelf-life and lost sales. Int. J. Prod. Res. 2020, forthcoming, 1-20. [CrossRef]

20. Seubert, F.; Stein, N.; Taigel, F.; Winkelmann, A. Making the newsvendor smart-Order quantity optimization with ANNs for a bakery chain. In Proceedings of the 26th Americas Conference on Information Systems (AMCIS 2020), Salt Lake City, UT, USA, 15-17 August 2020; Anderson, B.B., Thatcher, J., Meservy, R.D., Chudoba, K., Fadel, K.J., Brown, S., Eds.; Association for Information Systems: Atlanta, GA, USA, 2020; pp. 1-10.

21. Bakker, M.; Riezebos, J.; Teunter, R.H. Review of inventory systems with deterioration since 2001. Eur. J. Oper. Res. 2012, 221, 275-284. [CrossRef]

22. Janssen, L.; Claus, T.; Sauer, J. Literature review of deteriorating inventory models by key topics from 2012 to 2015. Int. J. Prod. Econ. 2016, 182, 86-112.

23. Etgar, M.; Malhotra, N.K. Determinants of price dependency: Personal and perceptual factors. J. Consum. Res. 1981, 8, 217-222. [CrossRef]

24. Steenkamp, J.B.E. Perceived quality of food products and its relationship to consummer preferences: Theory and measurement. J. Food Qual. 1986, 9, 373-373. [CrossRef]

25. Völckner, F.; Hofmann, J. The price-perceived quality relationship: A meta-analytic review and assessment of its determinants. Mark. Lett. 2007, 18, 181-196. [CrossRef]

26. Remmington, M.C.A. The Effect of Freezing and Refrigeration on Food Quality. Master's Thesis, Clemson University, Clemson, SC, USA, 2017.

27. Pantelides, C.C. Unified frameworks for optimal process planning and scheduling. In Foundations of Computer Aided Process Operations; Rippin, D.W.T., Hale, J., Davis, J.F., CACHE (Organization) and American Institute of Chemical Engineers, Eds.; CACHE: Williamsburg, MA, USA, 1994; pp. 253-274.

28. Castro, P.M.; Barbosa-Póvoa, A.P.; Matos, H.A. Optimal periodic scheduling of batch plants using RTN-based discrete and continuous-time formulations: A case study approach. Ind. Eng. Chem. Res. 2003, 42, 3346-3360. [CrossRef]

29. Joint FAO/WHO Codex Alimentarius Commission. In Codex Alimentarius; Food and Agriculture Organization of the United Nations: Rome, Italy, 2010.

30. GAMS Development Corporation. GAMS—A User's Guide, GAMS Release 24.2.1; GAMS Development Corporation: Washington, DC, USA, 2013.

31. GAMS Development Corporation. GAMS—The Solver Manuals, GAMS Release 24.2.1; GAMS Development Corporation: Washington, DC, USA, 2013.

32. ILOG, Inc. IBM ILOG CPLEX Optimization Studio CPLEX User's Manual-Version 12.7. 2016. Available online: https:/ /www.ibm. com/support/knowledgecenter/SSSA5P_12.7.0/ilog.odms.studio.help/pdf/usrcplex.pdf (accessed on 23 October 2020 ). 